\title{
PENGARUH PEMBERIAN EKSTRAK BUAH PARE (MOMORDICA CHARANTIA L.) PADA AIR MINUM TERHADAP KUALITAS TELUR BURUNG PUYUH (COTURNIX-COTURNIX JAPANICA)
}

\section{EFFECTS OF THE INCLUSION OF BITTER MELON (MOMORDICA CHARANTIA L.) FRUIT EXTRACT IN DRINKING WATER ON THE QUALITY OF QUAIL (COTURNIX COTURNIX JAPONICA) EGGS}

\author{
SS Siahaan1a, H Nur , dan Anggraeni
}

1Programstudi Peternakan Fakultas Agribisnis dan Teknologi Pangan Universitas Djuanda Bogor, Jl. Tol Ciawi No. 1, Kotak Pos 35 Ciawi, Bogor 16720.

aKorespondensi: Syailendara Syahputra Siahaan, E-mail: Syailendra.syahputra@unida.ac.id

\begin{abstract}
Egg quality is assessed from its external parameters including color, shape, weight and internal parameters including haugh unit (HU), yolk color, and albumin content. This study was aimed at assessing the quality of eggs of quails given drinking water containing bitter melon fruit extract. The study was conducted at a trial farm of Djuanda University, Bogor from February to March 2019. Onehundred quails aged 30 days were allocated into 4 treatments and 5 replicates in a completely randomized design. Treatments consisted of $0 \%$ inclusion of bitter melon fruit extract (R0, control), $2.5 \%$ inclusion of bitter melon fruit extract (R1), $5 \%$ inclusion of bitter melon fruit extract (R2), $7.5 \%$ inclusion of bitter melon fruit extract (R3), and $10 \%$ inclusion of bitter melon fruit extract (R4). Measurements were taken on egg index, shell weight, shell thickness, yolk color, and HU. Data were subjected to an analysis of variance and a Duncan test. Results showed that no significant effect of treatment was found in all parameters measured.
\end{abstract}

Key words: quail, bitter melon fruit extract, egg quality

\begin{abstract}
ABSTRAK
Kualitas telur dapat diketahui dengan cara mengukur kualitas eksterior yaitu warna, bentuk telur, bobot telur sedangkan interior meliputi haugh unit (HU), yolk, dan albumen telur. Penelitian ini bertujuan untuk mengetahui kualitas telur burung puyuh yang diberi ekstrak buah pare (Momordica Charantia L.). Penelitian ini dilaksanakan di kandang peternakan Universitas Djuanda Bogor, Jl. Tol Ciawi No. 1, Kotak Pos 35 Ciawi, Bogor 16720 dari bulan Februari-Maret 2019. Ternak yang digunakan dalam penelitian ini burung puyuh (coturnix-coturnix japonica) umur 30 hari sebanyak 100 ekor. Penelitian ini menggunakan rancangan acak lengkap (RAL) yang terdiri atas 4 perlakuan dan 5 ulangan. Perlakuan dalam penelitian ini RO $=0 \%$ ekstrak buah pare (Kontrol), R1= air minum dengan 2,5\% ekstrak buah pare, R3= air minum dengan 7.5\% ekstrak buah pare, dan R4= air minum dengan 10\% ekstrak buah pare. Data yang diperoleh dianalisis menggunakan Analysis of variance (ANOVA), bila data menunjukkan hasil berbeda nyata $(\mathrm{P}<0.05)$ dilanjutkan dengan uji Duncan. Peubah yang diamati dalam penelitian ini adalah indeks telur, bobot kerabang, tebal kerabang, warna yolk, dan haugh unit. Hasil penelitian menunjukkan pemberian ekstrak buah pare pada burung puyuh tidak berpengaruh terhadap semua peubah.
\end{abstract}

Kata kunci : Burung Puyuh, Ekstrak Buah Pare, Kualitas Telur

SS Siahaan, H Nur, dan Anggraeni.2020. Pengaruh Pemberian Ekstrak Buah Pare (Momordica Charantia L.) Pada Air Minum Terhadap Kualitas Telur Burung Puyuh (Coturnix- coturnix

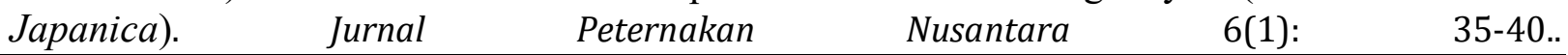




\section{PENDAHULUAN}

Telur merupakan salah satu produk hewani berasal dari ternak unggas dan sebagai bahan pangan berprotein tinggi, dan mudah didapatkan oleh masyarakat indonesia. Telur yang beredar di pasaran merupakan telur yang berasal dari induk muda dengan kualitas yang berbeda. Yuwanta (2010) menyatakan kualitas telur dipangaruhi oleh umur.

Telur merupakan bahan pangan yang mudah mengalami penurunan kualitas yang disebabkan oleh mikroorganisme. yuwanta (2010) menyatakan suhu, kelembapan dan kualitas kerabang telur merupakan penyebab penurunan kualitas telur selain dari lama penyimpanan. Semakin lama telur disimpan bobot telur akan menyusut dan putih telur menjadi encer.

Pare memiliki nilai ekonomi yang tinggi srbagai tanaman pangan sehingga berpotensial untuk dikembangkan. Pare sebagai feed additive herbal pada air minum serta sebagai antibiotik alami yang mampu menambah nafsu makan dan anti antelmintik yang mengandung momordisin, memordin, karantin, asam trikosanik, resin, asam resinat, steroid, vitamin A,B,dan C serta minyak lemak yang terdiri atas asam oleat, asam linoleat, asam stearat dan Loleostearat, karantin, hydroxytryptamine, serta vitamin A, B, dan C,.(Naid et al 2008). Tujuan dari penelitian ini untuk mengetahui kualitas telur puyuh yang diberi ekstrak buah pare.

\section{MATERI DAN METODE}

\section{Materi}

Penelitin dilaksanakan selama 35 hari, mulai pada tanggal 02 Februari sampai dengan tanggal 09 Maret 2019. Bertempat di kandang peternakan Universitas Djuanda Bogor.

Alat yang digunakan yaitu kandang, tempat pakan, tempat minum, timbangan digital, jangka sorong, yolk colour fan, mikro meter, Tabung gas, lampu, kantong plastik, kompor gas, panci besar, saringan, nasi, karung, baskom, koran, alat tulis, termometer, penggaris, pisau, parutan, keranjang telur, gelas ukur, panci. Materi pokok pada penelitian ini adalah burung puyuh.

\section{Perlakuan}

Perlakuan yang diberikan yaitu sebagai berikut: P0 : Pemberian ekstrak buah pare $0 \%$, P1 : Air minum dengan 2,5\%, P2 : Air minum dengan $5 \%$, P3 : Air minum dengan 7,5\%, P4 : Air minum dengan $10 \%$

\section{Rancangan Percobaan}

Rancangan yang digunakan dalam penelitian yaitu rancangan acak lengkap (RAL). Lima perlakuan dan empat ulangan. Dari jumlah perlakuan dan ulangan tersebut terdapat 20 kombinasi ulangan dengan satu unit kandang lima ekor puyuh. Berikut model matematika yang digunakan dalam penelitian (Hanafiah 2003).

$$
\mathrm{Y}_{i j}=\mu+\mathrm{T}_{i}+\varepsilon_{i j}
$$

Keterangan:

$\mathrm{Y}_{i j}=$ Nilai pengamatan dari perlakuan ke-i pada ulangan ke-j.(1,2,3,4)

$\mu=$ Nilai tengah umum .

$\mathrm{T}_{i}=$ Pengaruh persentase pemberian ekstrak buah pare ke-i.(1,2,3,4,5)

$\varepsilon_{i j}=$ Galat percobaan pada persentase pemberian ekstrak buah pare ke-i pada ulangan ke-j.

\section{Peubah yang Diamati}

1. Indeks Telur : Indeks telur didapat dari perbandingan antara lebar telur dengan panjang telur yang diukur menggunakan jangka sorong dikalikan dengan 100\%.

$$
\text { Indeks telur }=\underset{\text { Panjang telur }}{\text { lebar telur }} \times 100
$$

2. Bobot Kerabang: Bobot kerabang di dapat dengan menimbang bobot kerabang telur (g) menggunakan timbangan digital.

3. Tebal Kerabang :Tebal kerabang (mm) di hasilkan dengan mengukur menggunakan mikrometer. Pengukuran dilakukan pada bagian ujung tumpul, tengah dan ujung lancip telur kemudian dirata-ratakan.

4. Warna yolk: Warna yolk didaptkan dengan membandingkan warna yolk menggunakan alat egg yolk colour fan standar skala warna 1-15. 
5. Haugh Unit : Nilai Haugh Unit di hasilkan dengan cara mengukur tinggi albumen dan berat telur menggunakan Jangka sorong dan timbangan digital. Nilai Haugh unit dihasilakan dengan rumus: $\mathrm{HU}=100 \log \left(\mathrm{H}+7,57-1,7 \mathrm{~W}^{0,37}\right)$

Keterangan :

$\mathrm{HU}=$ Haugh Unit

$\mathrm{H}=$ Tinggi Albumen

$\mathrm{W}=$ Berat Telur (Card, 1975) disitasi (Sudibya 1989).

\section{Analisis Data}

Analisis data dilakukan dengan uji Anova. Bila menunjukkan pengaruh nyata $(\mathrm{P}<0,05)$ atau nyata $(\mathrm{P}<0,01)$ maka dilanjutkan dengan uji Duncan untuk mengetahui perbedaan antar perlakuan.

\section{Prosedur Pelaksanaan}

Kandang yang digunakan adalah kandang dengan sistem baterai yang terbuat dari kayu, kawat dan triplek sebagai penutup. Ukuran baterai puyuh yang digunakan yaitu berukuran 87 x 56 x35 cm. Baterai yang digunakan yaitu baterai susun 4 tingkat. Persiapan kandang meliputi alat pemeliharaan dan pembersihan kandang menggunakan disinfektan.

Persiapan kandang dilakukan dengan membersihkan, menyemprot kandang dan area sekitar dengan cairan desinfektan. Yang harus diperhatikan adalah temperatur kandang dengan idealnya berkisar 20-25 $\mathrm{C}$ dengan menggunakan lampu, tempat pakan dan tempat minum, ventilasi udara, sinar matahari, tata letak kandang diatur dekat dengan ventilasi udara atau sinar matahari agar kandang tidak lembab.

Sebelum puyuh di masukkan kedalam kandang, dilakukan persiapan minum untuk puyuh yang di campur dengan vitastres agar menormalkan kembali keadaan puyuh setelah dalam perjalanan. Selanjutnya seleksi puyuh sebelum masuk agar dapat memisahkan puyuh yang sehat dan tidak sehat, burung puyuh harus dalam keadaan sehat, normal, lincah, dan tidak cacat.

Pembuatan ekstrak buah pare dilakukan dengan cara terlebih dahulu memilih buah pare yang segar lalu di belah menjadi dua bagian dipisahkan biji dan daging. Setelah itu buah pare di cuci, di parut sampai halus lalu di saring di pisahkan air dengan ampas buah pare. Kemudian ekstrak buah pare didihkan selama
20 menit agar ekstrak buah pare dapat bertahan lama dalam penyimpanan.

Pemberian dilakukan pada jam 08.00 WIB pagi dengan jumlah pemberian pada Tabel 1 :

Tabel 1 pemberian ekstrak buah pare

\begin{tabular}{cccc}
\hline Perlakuan & $\begin{array}{c}\text { Ekstrak } \\
\text { buah } \\
\text { pare } \\
(\mathrm{ml})\end{array}$ & $\begin{array}{c}\text { Air } \\
\text { minum } \\
(\mathrm{ml})\end{array}$ & $\begin{array}{c}\text { Jumlah } \\
\text { pemberian } \\
(\mathrm{ml})\end{array}$ \\
\hline P0 & 0 & 2000 & 2000 \\
P1 & 50 & 1950 & 2000 \\
P2 & 100 & 1900 & 2000 \\
P3 & 150 & 1850 & 2000 \\
P4 & 200 & 1800 & 2000 \\
\hline
\end{tabular}

Pengambilan data dilakukan dengan cara mengumpulkan telur puyuh setiap hari pada pukul 06.00 WIB. Telur yang dihasilkan dari masing-masing perlakuan dicatat jumlahnya. Pengukuran panjang, lebar dan bobot telur dilakukan setiap hari. Sedangkan untuk pengukuran tebal albumen, yolk, bobot kerabang, dan tebal kerabang dilakukan seminggu sekali. Pengukuran telur menggunakan jangka sorong, mikrometer, timbangan digiital dan yolk colour fan.

\section{HASIL DAN PEMBAHASAN}

\section{Indeks Telur Puyuh}

Berdasarkan hasil analisis ragam diketahui bahwa pemberian ekstrak buah pare pada burung puyuh tidak berpengaruh nyata $(\mathrm{P}>0,05)$ terhadap indeks telur. Rataan indeks telur yang diperoleh berkisar antara 79,86 $\pm 0,83$ sampai 99,97 $\pm 26,01$. Indeks telur yang dihasilkan lebih tinggi dari penelitian Paryanta (2018) yaitu 77,46 $\pm 2,70 \%$ sampai $81,09 \pm 1,69$ $\%$. Sodak (2011) menyatakan nilai indeks telur semakin tinggi maka semakin bulat bentuk telur. Dengan semakin bulatnya telur membuat konsumen semakin tertarik mengkonsumsi karena konsumen atau masyarakat lebih suka dengan telur yang berbentuk bulat dibandingkan dengan yang berbentuk oval. 
Tabel 2 hasil peubah penelitian

\begin{tabular}{lccccc}
\hline Peubah & $\mathrm{R} 0$ & $\mathrm{R} 1$ & $\mathrm{R} 2$ & $\mathrm{R} 3$ & $\mathrm{R} 4$ \\
\hline Indeks telur & $84,02 \pm 6,26$ & $82,95 \pm 0,40$ & $79,58 \pm 0,76$ & $80,88 \pm 1,45$ & $81,23 \pm 1,61$ \\
Bobot kerabang & $1,70 \pm 0,09$ & $1,69 \pm 0,15$ & $1,68 \pm 0,11$ & $1,61 \pm 0,11$ & $1,67 \pm 0,12$ \\
Tebal kerabang & $0,44 \pm 0,67$ & $0,28 \pm 0,02$ & $0,29 \pm 0,02$ & $0,30 \pm 0,02$ & $0,29 \pm 0,02$ \\
Warna yolk & $4,16 \pm 0,70$ & $4,10 \pm 0,83$ & $4,20 \pm 1,09$ & $4,00 \pm 0,76$ & $3,80 \pm 1,12$ \\
Nilai haugh unit & $59,65 \pm 1,89$ & $58,15 \pm 1,70$ & $58,19 \pm 2,08$ & $58,77 \pm 2,23$ & $58,83 \pm 2,47$ \\
\hline
\end{tabular}

pada burung puyuh tidak berbeda nyata

\section{Bobot Kerabang Telur Puyuh}

Berdasarkan hasil sidik ragam diketahui bahwa pemberian ekstrak buah pare pada burung puyuh tidak berpengaruh nyata $(\mathrm{P}>0,05)$ terhadap bobot kerabang. Hasil penelitian ini memperlihatkan bahwa pemberian ekstrak buah pare tidak mempengaruhi pembentukan kerabang atau penyerapan mineral. Berdasarkan tabel 2 dapat dilihat bahwa urutan yang paling tertinggi adalah perlakuan R2 (ekstrak buah pare 5\%) dengan rataan $1,68 \pm 0,11$ tetapi secara statistik tidak berbeda nyata. Kerabang telur merupakan bagian paling luar telur dan keras terutama tersusun atas kalsium karbonat ( $\mathrm{CaC03})$. Kalsium karbonat berperan penting sebagai sumber utama kalsium $(\mathrm{Ca})$.

\section{Tebal Kerabang Telur Puyuh}

Berdasarkan hasil sidik ragam diketahui bahwa pemberian ekstrak buah pare pada burung puyuh tidak berpengaruh nyata $(\mathrm{P}>0,05)$ terhadap tebal kerabang. Rataan tebal kerabang yang diperoleh berkisar antara $0,27 \pm 0,03 \mathrm{~mm}$ sampai $0,30 \pm 0,03 \mathrm{~mm}$. Pemberian ekstrak buah pare dengan urutan tertinggi dapat dilihat pada tabel 1 perlakuan $\mathrm{R} 2(5 \%)$ dengan rataan $0,29 \pm 0,02$. (Sudaryani 2006) suhu lingkungan dengan kerabang telur mempunyai hubungan yang berbanding terbalik, suhu yang tinggi akan mengurangi ketebalan kerabang telur. Hasil yang diperoleh lebih tinggi dari penelitian Paryanta (2018) yaitu puyuh yang diberi larutan daun katuk memiliki ketebalan kerabang telur berkisar antara 0,21 $\pm 0,02 \mathrm{~mm}$ sampai $0,29 \pm 0,12 \mathrm{~mm}$. Kandungan kalsium pada pakan dapat mempengaruhi berat kerabang dan ketebalan kerabang (Krebeab et al, 2009).

\section{Warna Yolk Telur Puyuh}

Berdasarkan hasil penelitian analisis ragam diketahui bahwa pemberian ekstrak buah pare
$(\mathrm{P}>0,05)$ terhadap warna yolk. Rataan warna yolk yang diperoleh bekisar 3,08 $\pm 0,99$ sampai $3,66 \pm 0,47$. Berdasarkan tabel 2 dapat dilihat bahwa urutan yang paling tertinggi terdapat pada perlakuan R2 (5\%) tetapi secara statistik tidak berbeda nyata. Hal ini diduga karena terdapat $\beta$-caroten pada buah pare. Sahara (2011) menyatakan warna yolk sangat dipengaruhi oleh zat warna karetenoid. Pigmen karetenoid akan merefleksikan warna kuning, orange atau merah. Hasil penelitian ini lebih rendah dari hasil penelitian Paryanta (2018) yaitu burung puyuh yang diberi larutan katuk memiliki rataan warna kuning telur antara $7,67 \pm 0,58$ sampai $8,18 \pm 0,21$

\section{Nilai Haugh Unit Telur Puyuh}

Berdasarkan hasil analisis ragam diketahui bahwa pemberian ekstrak buah pare pada air minum terhadap burung puyuh tidak berpengaruh nyata $(\mathrm{P}>0,05)$ terhadap nilai haugh unit telur puyuh. Hasil ini lebih rendah dari penelitian Paryanta (2018) yaitu puyuh yang diberi larutan daun kelor memiliki rataan $94,00 \pm 4,43$ sampai 97,06 $\pm 1,34$. Pada tabel 2 dapat dilihat urutan yang paling tertinggi adalah perlakuan R2 (5\%) dengan rataan yaitu $58,19 \pm 2,08$. Nilai kualitas haugh unit pada penelitian ini termasuk kualitas B. Tingakatan kualitas telur berdasarkan nilai $\mathrm{HU}$ yaitu jika $>72$ termasuk kualitas AA, nilai HU 60-71 termasuk kualitas A dan nilai HU antara 31-59 termasuk kualitas B (USDA 1964; Brown 2000). Faktor yang mempengaruhi nilai haugh unit adalah tinggi albumen, suhu dan umur penyimpanan. Yuwanta (2010) Haugh unit merupakan satuan nilai putih telur dengan cara menghitung logaritma pada putih telur ditransformasikan kedalam nilai koreksi dari fungsi telur. 


\section{KESIMPULAN DAN IMPLIKASI}

\section{Kesimpulan}

Pemberian ekstrak buah pare dapat diberikan sampai dosis 5\%.

\section{Implikasi}

Penelitian lebih lanjut bisa dilaksanakan dengan menambah dosis pada ekstrak buah pare lebih dari $10 \%$ serta waktu penelitian yang diperpanjang.

\section{DAFTAR PUSTAKA}

Hanafiah K.A., 2003. Rancangan Percobaan Teori dan Aplikasi). Raja Grafindo Persada, Jakarta.

Krebeab E, France J, Kwakkel RP, Leeson S, Kuhi HD, Dijkstra J. 2009.Development and evaluation of a dynamic model of calcium and phosphorus flows in layer. Poult Sci. 88 (3):680-689.

Paryanta. 2018. Kualitas Telur Burung Puyuh (coturnix-coturnix japonica) yang diberi Larutan Daun Kelor (Moringa oleifera L)[skripsi]. Program Studi Peternakan. Fakultas Pertanian. Universitas Djuanda Bogor.

Sahara E. 2011. Penggunaan kepala udang sebagai sumber pigmen dan kitin dalam pakan ternak. Jurnal Agribisnis Dan Industri Peternakan (1) 1: 31-35.

Sodak FJ. 2011. Karakteristik Fisik Dan Kimia Telur Ayam Arab Pada Dua Peternakan Di Kabupaten Tulungagung. Jawa Timur.
[Skripsi]. Departemen Ilmu Produksi Dan Teknologi. Fakultas Peternakan. Intitut Pertanian Bogor.

Sudaryani T. 2006. Kualitas Telur. Jakarta (ID): PT Penebar Swadaya.

Sudibyo S. 1989. Aspek Fungsi dan Teknis Post Occupancy Evaluation dan Beberapa Metodologi Penelitian. Usakti : Jakarta

Suartha IN, Swantara IMD, Rita WS. 2016. Ekstrak etanol dan fraksi heksan buah pare (Momordica charantia) sebagai penurun kadar glukosa darah tikus diabetes. Jurnal Veteriner 17 (1): 30-36.

Yuwanta T. 2010. Telur dan Kualitas Telur. Gajah Mada University Press, Yogyakarta. 